\title{
Comparison of Predictive Equations for Resting Energy Expenditure in Overweight and Obese Adults
}

\author{
Erick Prado de Oliveira, , 2 Fábio Lera Orsatti, ${ }^{1,3}$ Okesley Teixeira,, ${ }^{1,2}$ \\ Nailza Maestá, ${ }^{1}$ and Roberto Carlos Burini ${ }^{1}$ \\ ${ }^{1}$ Department of Public Health, Centre for Physical and Nutritional Metabolism (CeMENutri), São Paulo State University (UNESP), \\ District of Rubião Junior s/no, 18618-970 Botucatu, SP, Brazil \\ ${ }^{2}$ Department of Pathology, São Paulo State University (UNESP), District of Rubião Junior s/no, 18618-900 Botucatu, SP, Brazil \\ ${ }^{3}$ Exercise Biology Laboratory (BioEx), Health Science Institute, Triângulo Mineiro Federal University (UFTM), 38025-440 Uberaba, \\ MG, Brazil
}

Correspondence should be addressed to Erick Prado de Oliveira, erick_po@yahoo.com.br

Received 11 February 2011; Revised 14 April 2011; Accepted 24 May 2011

Academic Editor: Jack A. Yanovski

Copyright () 2011 Erick Prado de Oliveira et al. This is an open access article distributed under the Creative Commons Attribution License, which permits unrestricted use, distribution, and reproduction in any medium, provided the original work is properly cited.

Objective. To compare values from predictive equations of resting energy expenditure (REE) with indirect calorimetry (IC) in overweight and obese adults. Methods. Eighty-two participants aged 30 to 60 years old were retrospectively analyzed. The persons had a body mass index $\geq 25 \mathrm{~kg} / \mathrm{m}^{2}$. REE was estimated by IC and other five equations of the literature (Harris and Benedict, WHO1, WHO2, Owen, Mifflin). Results. All equations had different values when compared to those of IC. The best values were found by Harris and Benedict, WHO1, and WHO2, with high values of intraclass correlation coefficient and low values of mean difference. Furthermore, WHO1 and WHO2 showed lower systematic error and random. Conclusion. No predictive equations had the same values of REE as compared to those of indirect calorimetry, and those which least underestimated REE were the equations of WHO1, WHO2, and Harris and Benedict. The next step would be to validate the new equation proposed.

\section{Introduction}

Resting energy expenditure (REE) is the major component of total energy expenditure, considering the amount of energy the body requires to keep its vital functions [1]. REE is usually measured by indirect calorimetry (IC), a noninvasive method, which is based on the consumption of $\mathrm{O}_{2}$ and production of $\mathrm{CO}_{2}$. However, due to the high cost of the equipment, equations are usually used to estimate energy expenditure [2-6].

Obese persons usually have extremely variable REE and the ideal method to estimate it is still controversial [7]; there are still no ideal equations for its measurement $[8,9]$. It is known that prevalence of overweight and obesity is high and has been increasing considerably [10]; obesity is one of the main causes of cardiovascular diseases [11]. Thus, programs for weight loss are advisable and must include hypocaloric diets based mainly on REE [12].
Studies available present conflicting results, making it difficult to establish the best formula to estimate total energy expenditure $[13,14]$. The most widely used predictive equations are those developed by Harris and Benedict (H-B) [7] although these can often lead to an overestimation of the caloric needs in health people [15].

Luis et al. studied 200 obese individuals and reported that the equation of the World Health Organization (WHO) [6] was the one that least underestimated the energy expenditure of these participants [16]. This finding was also reported by a Brazilian study with women whose mean body mass index (BMI) indicated overweight $\left(29 \pm 4 \mathrm{~kg} / \mathrm{m}^{2}\right)$ [17]. However, another study with subjects which had the same BMI mean showed that the equation of WHO overestimated REE values [18].

The equation of Owen et al. [2] is the most suitable for normal weight individuals [19], and, with some restrictions, the equation of Mifflin is indicated for normal, overweight 
and obese people in the United States [12, 15]; however, this might not be true in other populations. Based on studies previously mentioned [16-18], there are no suitable equations for overweight and obese persons.

Based on these data, it can be assumed that there are no definite predictive equations of REE which are suitable to the BMI of the individuals. Therefore, the objective of the present study was to compare values from predictive equations of REE with those from indirect calorimetry in overweight/obesity adults.

\section{Methodology}

2.1. Sample. A descriptive cross-sectional study was conducted in a subgroup of participants clinically screened for the lifestyle modification program "Mexa-se Pró-Saúde (Move for Health)," from 2006 to 2007. This program is offered to patients with noncommunicable chronic diseases and consists of regular physical exercise and nutritional counseling. The Metabolism, Exercise and Nutrition Center (CeMENutri) conducts this program since 1992, in Botucatu, a city located in the center of Sao Paulo State.

The following inclusion criteria were used: sedentary individuals, BMI $\geq 25 \mathrm{~kg} / \mathrm{m}^{2}$, and ages between 30 and 60 years old. A total of 82 participants were studied, 40 of them were male and 42 were female. All individuals were overweight or obese adults. The participants characteristics are shown in Table 1 .

All the subjects signed a free consent form, and the research project was approved by the Research Ethics Committee. The studied patients were part of projects approved by the Ethics Research Committee of the Medical School of Botucatu-UNESP (April 5th, 2004-resolution 196 of October 10th, 1996).

2.2. Anthropometric Evaluation. Body mass (kg) was measured using platform-type anthropometric scale (Filizola, Brasil), with graduation of $0.1 \mathrm{~kg}, 150 \mathrm{~kg}$ capacity. Height (m) was determined by portable wall-mounted stadiometer (SECA) with $0.1 \mathrm{~cm}$ accuracy. The BMI was calculated using the relation body mass $(\mathrm{kg}) /$ height $^{2}(\mathrm{~m})$ according to the World Health Organization [20].

2.3. Resting Energy Expenditure. REE was evaluated by indirect calorimetry of open circuit using the mixing-chamber system, with Quinton equipment (QMC). The machine was turned on 30 minutes before the exams for warm-up, suitable stabilization, and calibration of the $\mathrm{O}_{2}$ and $\mathrm{CO}_{2}$ analyzers with known gas concentration [21]. Patients underwent evaluation in the morning after a 12-hour fast, having slept six to eight hours and without having practiced intense physical activity 24 hours prior to the exam. The evaluation was performed in a silent environment with dim lighting and controlled temperature [21]. There was a 10-minute acclimatization period for reading stabilization, and then $\mathrm{VO}_{2}$ and $\mathrm{VCO}_{2}$ were measured for a period of 20 minutes $[22,23]$. REE was calculated using Weir's equation [24].
TABLE 1: Distribution of variables according to gender.

\begin{tabular}{lccc}
\hline & Total $(n=82)$ & Men $(n=40)$ & Women $(n=42)$ \\
\hline Age (years) & $44.9 \pm 8.3$ & $45.2 \pm 8.4$ & $44.7 \pm 8.3$ \\
Weight $(\mathrm{kg})$ & $87.8 \pm 18.6$ & $95.3 \pm 18.1$ & $80.7 \pm 16.2$ \\
Height $(\mathrm{cm})$ & $164.9 \pm 11.4$ & $173.6 \pm 7.8$ & $156.7 \pm 7.4$ \\
BMI $\left(\mathrm{kg} / \mathrm{m}^{2}\right)$ & $32.1 \pm 5.2$ & $31.5 \pm 5$ & $32.7 \pm 5.4$ \\
REE $(\mathrm{IC})(\mathrm{kcal} / \mathrm{d})$ & $1896 \pm 419$ & $2128 \pm 351$ & $1675 \pm 356$ \\
\hline
\end{tabular}

Demographic and anthropometric data were used to calculate REE using predictive equations of Mifflin et al. [3], Harris and Benedict [5], WHO1 [6], WHO2 [6], and Owen et al. [2, 4] (Table 2).

2.4. Statistical Analyses. The results were shown as mean \pm standard deviation. Anova one-way was used in order to compare the differences between REE values from equations and indirect calorimetry, then Scheffe post hoc test was used to identify which equation value was equal to the REE value measured by indirect calorimetry. Pearson's correlation analysis between the values obtained by the equations and indirect calorimetry was performed. Multiple linear regression was used to determine which equation would be more suitable for the studied population. Percentages of the difference among values of REE, indirect calorimetry, and predictive equations were calculated.

Intraclass correlation coefficient and Bland-Altman plot were used to compare the differences between REE values from equations and indirect calorimetry. Significance level was at $P<0.05$.

\section{Results}

For overweight and obese persons of this study, all equations had different values when compared to those of indirect calorimetry. However, the values were similar among HarrisBenedict's, WHO1 and WHO2's equations and between Mifflin's and Owen's equations (Table 3 ).

The values of REE obtained from the equations and indirect calorimetry had a strong and significant positive correlation $(P<0.05)$ with all the equations (Table 4$)$.

The equations underestimated IC by $5 \%$ to $12 \%$, in which WHO1, WHO2, and Harris and Benedict were the equations which least underestimated the real value of REE as follows: $-5.15 \%,-4.7 \%$, and $-7.43 \%$, respectively. The equations of Owen $(-13.28 \%)$ and Mifflin $(-13.56 \%)$ were those which most underestimated REE value. No significant difference was found between genders (data not shown).

For the equations studied, only WHO1 and WHO2 showed values of confidence interval for percent mean difference (CI 95\% d\%) below 10\% and lower values of limits of agreement for percent mean difference (LA 95\% d\%), reflecting lower systematic error and random, respectively. However, the precision values (LA 95\% d\%) were high for all equations (Table 5). In the concordance analyses, the best values were found by Harris and Benedict, WHO1 and 
TABLE 2: Equations used to compare REE with values of indirect calorimetry.

\begin{tabular}{|c|c|}
\hline Authors & Equations \\
\hline \multirow{2}{*}{ Mifflin et al. [3] } & $\sigma^{7}(9.99 \times \mathrm{W})+(6.25 \times \mathrm{H})-(4.92 \times \mathrm{A})+5$ \\
\hline & 우 $(9.99 \times \mathrm{W})+(6.25 \times \mathrm{H})-(4.92 \times \mathrm{A})-161$ \\
\hline \multirow{2}{*}{ Harris and Benedict [5] } & $\sigma^{7} 66.47+(13.75 \times \mathrm{W})+(5 \times \mathrm{H})-(6.75 \times \mathrm{A})$ \\
\hline & q $655.0955+(9.5634 \times \mathrm{W})+(1.8496 \times \mathrm{H})-(4.6756 \times \mathrm{A})$ \\
\hline \multirow{6}{*}{ FAO/WHO/UNU [6] } & Only weight (WHO1) \\
\hline & $\sigma^{7}(11.6 \times W)+879$ \\
\hline & 우 $(8.7 \times W)+829$ \\
\hline & Weight and height (WHO2) \\
\hline & $\sigma^{\top}(11.3 \times \mathrm{W})+(16 \times \mathrm{H}(\mathrm{m}))+901$ \\
\hline & q $(8.7 \times \mathrm{W})-(25 \times \mathrm{H}(\mathrm{m}))+865$ \\
\hline \multirow{2}{*}{ Owen et al. ([2] $\sigma^{7}$ and [4] $\left.{ }^{\prime}\right)$} & $\sigma^{7} 879+(10.2 \times W)$ \\
\hline & q $795+(7.18 \times W)$ \\
\hline
\end{tabular}

$\mathrm{W}=$ weight $(\mathrm{kg}), \mathrm{H}=$ height $(\mathrm{cm}), \mathrm{A}=$ age (years).

TABLE 3: Comparison of REE values from predictive equations and indirect calorimetry.

\begin{tabular}{lcccccc}
\hline & REE (IC) & Mifflin & Harris and Benedict & WHO1 & WHO2 & Owen \\
\hline Total & $1896 \pm 418^{\mathrm{a}}$ & $1607 \pm 304^{\mathrm{b}}$ & $1718 \pm 329^{\mathrm{c}}$ & $1756 \pm 303^{\mathrm{c}}$ & $1765 \pm 310^{\mathrm{c}}$ & $1607 \pm 284^{\mathrm{b}}$ \\
Men & $2128 \pm 35^{\mathrm{a}}$ & $1820 \pm 233^{\mathrm{b}}$ & $1940 \pm 302^{\mathrm{c}}$ & $1993 \pm 340^{\mathrm{c}}$ & $2014 \pm 334^{\mathrm{c}}$ & $1851 \pm 185^{\mathrm{b}}$ \\
Women & $1675 \pm 356^{\mathrm{a}}$ & $1405 \pm 213^{\mathrm{b}}$ & $1508 \pm 184^{\mathrm{c}}$ & $1531 \pm 141^{\mathrm{c}}$ & $1528 \pm 140^{\mathrm{c}}$ & $1374 \pm 117^{\mathrm{b}}$ \\
\hline
\end{tabular}

Different letters $=P<0.05$ (no comparison between gender).

a , b, c Anova one-way and Sheffe post-hoc test.

WHO2, with high values of intraclass correlation coefficient (ICC) and low values of mean difference (d) (Table 5).

Equations with the following variables-age, gender, BMI, body weight, and height - were proposed. The equations with the best association with indirect calorimetry were those which included weight and gender without $\left(r^{2}=0.67\right)$ height; weight and gender with $\left(r^{2}=0.67\right)$ height; and that including weight, gender, height and age $\left(r^{2}=0.68\right)$. We suggest the equation $\mathrm{REE}=475.3+(14.9 \times \mathrm{W})+(235.8 \times \mathrm{G})$, in which $\mathrm{W}=$ weight $(\mathrm{kg})$ and $\mathrm{G}=$ gender $(0=$ woman and $1=$ man); it should be a better choice due to its easy applicability and fewer variables (Table 6).

\section{Discussion}

For overweight and obese individuals, an underestimation of REE by $167.4 \mathrm{kcal}(8.83 \%)$ was observed using all the equations tested in this study. Both equations of WHO and the equation of Harris and Benedict were those which least underestimated the values of IC, while the equations of Owen and Mifflin were those which most underestimated it. The selection of these equations is due to the fact that they are the most used equations in the general population, and that they have already been evaluated in another Brazilian studies $[17,18]$.

Fett et al. conducted a study comparing the same predictive equations of the present study with the REE measured by indirect calorimetry. Women whose BMI ranged from normal weight to obese with mean value of BMI, classified
TABLE 4: Correlation of REE values from predictive equations and indirect calorimetry.

\begin{tabular}{lccccc}
\hline & Mifflin & $\begin{array}{c}\text { Harris and } \\
\text { Benedict }\end{array}$ & WHO1 & WHO2 & Owen \\
\hline $\begin{array}{l}\text { Harris and } \\
\text { Benedict }\end{array}$ & 0.99 & & & & \\
WHO1 & 0.96 & 0.97 & & & \\
WHO2 & 0.96 & 0.97 & 1.00 & & \\
Owen & 0.95 & 0.95 & 0.99 & 0.99 & \\
REE (IC) & 0.80 & 0.78 & 0.79 & 0.78 & 0.78 \\
\hline
\end{tabular}

All values were statistically significant $(P<0.05)$.

as overweight, were selected for the study [17]. The authors reported similar results to our study, in which all equations underestimated REE measured by indirect calorimetry. They also reported that the WHOl's equation underestimated REE by $3 \%$ and the Harris-Benedict's and WHO2's equations underestimated REE by $4 \%$. These two equations showed less underestimation of REE at the present study. Owen's equation was the one that most underestimated (16\%) it, which is also in agreement to our findings.

Another study has also corroborated our findings. Luis et al. studied 200 obese individuals and reported that the equations of Owen, Harris, and WHO underestimated REE and the best equation was WHO [16]. In a study with an indigenous population, Valencia et al. reported that the WHO equation (only weight) overestimated REE by $9.8 \%$, 
TABLE 5: Analysis of the intraclass correlation coefficient (ICC) and Bland-Altman plot of predictive equations for REE.

\begin{tabular}{|c|c|c|c|c|c|c|c|c|c|c|}
\hline Equations & ICC & ICC CI 95\% & $\mathrm{d}$ & CI 95\% d & SD d & LA 95\% & $\mathrm{d} \%$ & CI 95\% d\% & $\mathrm{SD} d \%$ & LA 95\% d $\%$ \\
\hline Harris and Benedict & 0.76 & $0.65 ; 0.84$ & -177.8 & $-235.8 ;-120.5$ & 260.6 & $-688.6 ; 333.1$ & -8.9 & $-12.3 ;-5.5$ & 15.3 & $-39.0 ; 21.2$ \\
\hline Mifflin & 0.76 & $0.65 ; 0.84$ & -289.1 & $-344.8 ;-233.3$ & 250.6 & $-786.4 ; 208.1$ & -15.6 & $-18.9 ;-12.3$ & 14.8 & $-44.8 ; 13.4$ \\
\hline Owen & 0.72 & $0.60 ; 0.81$ & -289.3 & $-348.1 ;-230.6$ & 267.2 & $-813.2 ; 234.4$ & -15.4 & $-18.8 ;-12.0$ & 15.3 & $-45.5 ; 14.7$ \\
\hline WHO1 & 0.75 & $0.64 ; 0.83$ & -139.9 & $-196.8 ;-83$ & 259.0 & $-647.6 ; 367.7$ & -6.4 & $-9.8 ;-3.2$ & 15.1 & $-36.0 ; 23.0$ \\
\hline WHO2 & 0.75 & $0.64 ; 0.83$ & -131.3 & $-188.4 ;-74.1$ & 260.0 & $-640.8 ; 378.2$ & -6.0 & $-9.4 ;-2.7$ & 15.1 & $-35.7 ; 23.6$ \\
\hline
\end{tabular}

ICC = intraclass correlation coefficient; ICC CI 95\% = confidence interval for ICC; $\mathrm{d}$ (mean difference); CI 95\% for $\mathrm{d}=$ confidence interval for mean difference; $\mathrm{SD}=$ standard derivation; LA $95 \%$ = limits of agreement for mean difference; $\mathrm{d} \%=$ percent mean difference.

TABle 6: Predictive equations proposed in this study using age, gender, BMI, height, and body weight variables.

\begin{tabular}{|c|c|c|c|c|}
\hline & Equations & $R^{2}$ & $P$ & $\begin{array}{c}\text { Standard } \\
\text { Deviation }\end{array}$ \\
\hline Age (years) & $\mathrm{REE}=2250-(7.9 \times \mathrm{A})$ & 0.02 & 0.16 & - \\
\hline Gender $\left(1=\sigma^{\top}\right.$ and $\left.0=q\right)$ & $\mathrm{REE}=1675.2+(453.2 \times \mathrm{G})$ & 0.30 & $<0.01$ & 353.2 \\
\hline BMI & $\mathrm{REE}=809.7+(33.8 \times \mathrm{BMI})$ & 0.18 & $<0.01$ & 381.7 \\
\hline Height $(\mathrm{cm})$ & $\mathrm{REE}=-2192.1+(24.8 \times \mathrm{H})$ & 0.45 & $<0.01$ & 311.4 \\
\hline Weight $(\mathrm{kg})$ & $\mathrm{REE}=368.9+(17.4 \times \mathrm{W})$ & 0.60 & $<0.01$ & 267.3 \\
\hline Weight + Gender & $\mathrm{REE}=475.3+(14.9 \times \mathrm{W})+(235.8 \times \mathrm{G})$ & 0.67 & $<0.01$ & 245.3 \\
\hline Weight + Gender + Height & $\mathrm{REE}=-245.3+(13.6 \times \mathrm{W})+(165.8 \times \mathrm{G})+(5.3 \times \mathrm{H})$ & 0.67 & $<0.01$ & 244.6 \\
\hline Weight + Gender + Height + Age & $\mathrm{REE}=-795.9+(14.5 \times \mathrm{W})+(127.3 \times \mathrm{G})+(6.5 \times \mathrm{H})+(6.1 \times \mathrm{A})$ & 0.68 & $<0.01$ & 241.7 \\
\hline
\end{tabular}

$\mathrm{W}=$ weight $(\mathrm{kg}), \mathrm{H}=$ height $(\mathrm{cm}), \mathrm{A}=$ age (years), $\mathrm{G}=$ gender in which $1=$ male and $0=$ female, $\mathrm{BMI}=$ Body Mass Index.

$9.6 \%, 7.8 \%$, and $5.5 \%$ in underweight, normal weight, overweight, and obese individuals, respectively, which shows that this equation is more accurate for obese people [25].

However, other studies have shown opposite results. Women aged 20 to 40 years old with mean BMI classified as overweight presented overestimation of REE when compared to that of Harris' and WHO's equations [18]. Other study conducted with women from Rio de Janeiro compared values from WHO' and Harris's equations to those from IC. The equations of Harris and Benedict overestimated REE by $18.9 \%$ and WHO by $12.5 \%$ [26]. Therefore, further studies are required in order to define the population for which the equation of WHO should be applied.

The equations which most underestimated the population of the present study were Mifflin and Owen. The Mifflin's equation was developed using data collected from 498 individuals classified as normal, overweight, obese, or seriously obese [3]. This equation would be the most suitable for American individuals with BMI between $25-40 \mathrm{~kg} / \mathrm{m}^{2}$ and aged 16 to 65 years old $[12,15]$. However, a good relationship between this equation and overweight individuals was not observed in the present study. In fact, a consensus has not been reached on the use of the Mifflin's equation for obese individuals, and this equation has also proved to be highly applicable for normal weight individuals [15]. The underestimation using Owen equation was already expected, as it is the most reliable equation for normal weight populations, which present lower REE than obese individuals [19].

We suggested a proposal equation for overweight/obese adults, but this new equation needs to be validated in another sample of overweight/obese Brazilian individuals (second validation).

The present study had some limiting factors. Only BMI was used to evaluate body composition of the individuals. Although the lean body mass is the major component of REE, its usage has no additional benefits in predicting REE [12]. Besides, the individuals were not physically active and would hardly have an increase in BMI due to higher muscle mass.

\section{Conclusion}

No predictive equations of the literature used in this study had the same values of REE as compared to those of indirect calorimetry, and those which least underestimated REE were the equations of WHO1, WHO2, and Harris and Benedict. The next step would be to validate the new equation proposed.

\section{Abbreviations}

REE: Resting energy expenditure

IC: Indirect calorimetry

BMI: Body mass index

W: Weight

G: Gender.

\section{Conflict of Interests}

No conflict of interests was reported by the authors. 


\section{Acknowledgments}

The authors gratefully acknowledge the financial support of CAPES and CNPq and GAP (Grupo de Apoio à Pesquisa) of the Botucatu School of Medicine for the English assistance.

\section{References}

[1] E. E. da Rocha, V. G. Alves, and R. B. da Fonseca, "Indirect calorimetry: methodology, instruments and clinical application," Current Opinion in Clinical Nutrition and Metabolic Care, vol. 9, no. 3, pp. 247-256, 2006.

[2] O. E. Owen, E. Kavle, R. S. Owen et al., "A reappraisal of caloric requirements in healthy women," American Journal of Clinical Nutrition, vol. 44, no. 1, pp. 1-19, 1986.

[3] M. D. Mifflin, S. T. St Jeor, L. A. Hill, B. J. Scott, S. A. Daugherty, and Y. O. Koh, "A new predictive equation for resting energy expenditure in healthy individuals," American Journal of Clinical Nutrition, vol. 51, no. 2, pp. 241-247, 1990.

[4] O. E. Owen, J. L. Holup, D. A. D’Alessio et al., "A reappraisal of the caloric requirements of men," American Journal of Clinical Nutrition, vol. 46, no. 6, pp. 875-885, 1987.

[5] J. A. Harris and F. G. Benedict, A Biometric Study of Basal Metabolism in Man, Carnegie Institute of Washington, Washington, DC, USA, 1919.

[6] $\mathrm{FAO} / \mathrm{WHO} / \mathrm{UNU}$, "Energy and protein requirements: report of a joint FAO/WHO/UNU expert consiltation," World Health Organization Technical Report Series, vol. 724, pp. 1-206, 1985.

[7] V. G. F. Alves, E. E. M. da Rocha, M. C. Gonzalez, R. B. da Fonseca, M. H. Silva, and C. A. Chiesa, "Assessement of resting energy expenditure of obese patients: comparison of indirect calorimetry with formulae," Clinical Nutrition, vol. 28, no. 3, pp. 299-304, 2009.

[8] L. M. Horie, M. C. Gonzalez, R. S. Torrinhas, I. Cecconello, and D. L. Waitzberg, "New specific equation to estimate resting energy expenditure in severely obese patients," Obesity, vol. 19, no. 5, pp. 1090-1094, 2011.

[9] E. E. da Rocha, V. G. Alves, M. H. Silva, C. A. Chiesa, and R. B. da Fonseca, "Can measured resting energy expenditure be estimated by formulae in daily clinical nutrition practice?" Current Opinion in Clinical Nutrition and Metabolic Care, vol. 8, no. 3, pp. 319-328, 2005.

[10] C. L. Ogden, M. D. Carroll, L. R. Curtin, M. A. McDowell, C. J. Tabak, and K. M. Flegal, "Prevalence of overweight and obesity in the United States, 1999-2004," Journal of the American Medical Association, vol. 295, no. 13, pp. 1549-1555, 2006.

[11] C. J. Lavie, R. V. Milani, and H. O. Ventura, "Obesity and cardiovascular disease. risk factor, paradox, and impact of weight loss," Journal of the American College of Cardiology, vol. 53, no. 21, pp. 1925-1932, 2009.

[12] P. J. Weijs, "Validity of predictive equations for resting energy expenditure in US and Dutch overweight and obese class I and II adults aged 18-65 y," American Journal of Clinical Nutrition, vol. 88, no. 4, pp. 959-970, 2008.

[13] C. Alberda, L. Snowden, L. Mccargar, and L. Gramlich, "Energy requirements in critically III patients: how close are our estimates?" Nutrition in Clinical Practice, vol. 17, no. 1, pp. 38-42, 2002.

[14] A. M. Malone, "Methods of assessing energy expenditure in the intensive care unit," Nutrition in Clinical Practice, vol. 17, no. 1, pp. 21-28, 2002.

[15] D. C. Frankenfield, W. A. Rowe, J. S. Smith, and R. N. Cooney, "Validation of several established equations for resting metabolic rate in obese and nonobese people," Journal of the American Dietetic Association, vol. 103, no. 9, pp. 1152$1159,2003$.

[16] D. A. de Luis, R. Aller, O. Izaola, and E. Romero, "Prediction equation of resting energy expenditure in an adult spanish population of obese adult population," Annals of Nutrition and Metabolism, vol. 50, no. 3, pp. 193-196, 2006.

[17] C. A. Fett, W. C. Fett, and J. S. Marchini, "Resting energy expenditure measured vs. estimated and this relationship with body composition in women," Arquivos Brasileiros de Endocrinologia \& Metabologia, vol. 50, no. 6, pp. 1050-1058, 2006.

[18] V. Wahrlich and L. A. Anjos, "Validation of predictive equations of basal metabolic rate of women living in Southern Brazil," Revista de Saude Publica, vol. 35, no. 1, pp. 39-45, 2001.

[19] M. Siervo, V. Boschi, and C. Falconi, "Which REE prediction equation should we use in normal-weight, overweight and obese women?" Clinical Nutrition, vol. 22, no. 2, pp. 193-204, 2003.

[20] WHO, "Physical status: the use and interpretation of anthropometry," World Health Organization Technical Report Series, vol. 854, pp. 1-452, 1995.

[21] C. Compher, D. Frankenfield, N. Keim, and L. Roth-Yousey, "Best practice methods to apply to measurement of resting metabolic rate in adults: a systematic review," Journal of the American Dietetic Association, vol. 106, no. 6, pp. 881-903, 2006.

[22] M. A. Stokes and G. L. Hill, "A single, accurate measurement of resting metabolic expenditure," Journal of Parenteral and Enteral Nutrition, vol. 15, no. 3, pp. 281-287, 1991.

[23] T. R. Isbell, R. C. Klesges, A. W. Meyers, and L. M. Klesges, "Measurement reliability and reactivity using repeated measurements of resting energy expenditure with a face mask, mouthpiece, and ventilated canopy," Journal of Parenteral and Enteral Nutrition, vol. 15, no. 2, pp. 165-168, 1991.

[24] J. B. Weir, "New methods for calculating metabolic rate with special reference to protein metabolism," The Journal of Physiology, vol. 109, no. 1-2, pp. 1-9, 1949.

[25] M. E. Valencia, S. Y. Moya, G. McNeill, and P. Haggarty, "Basal metabolic rate and body fatness of adult men in northern Mexico," European Journal of Clinical Nutrition, vol. 48, no. 3, pp. 205-211, 1994.

[26] C. M. Cruz, A. F. da Silva, and L. A. dos Anjos, "Basal metabolic rate is overestimated by predictive equation in college-age women of Rio de Janeiro, Brazil," Archivos Latinoamericanos de Nutrición, vol. 49, no. 3, pp. 232-237, 1999. 


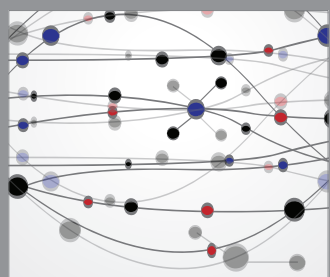

The Scientific World Journal
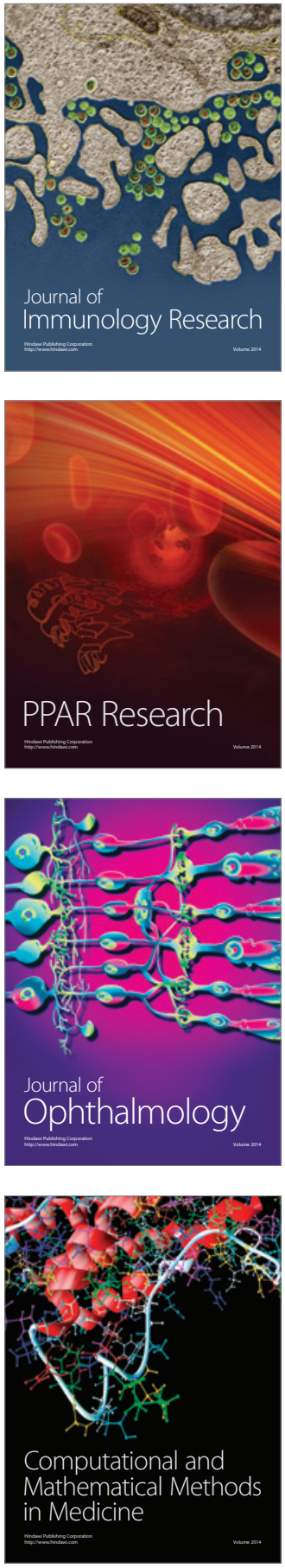

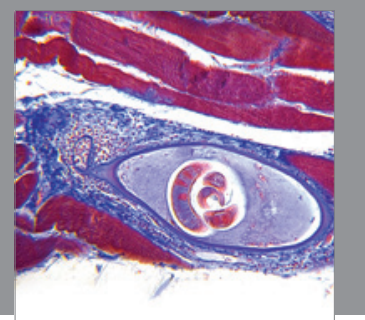

Gastroenterology

Research and Practice
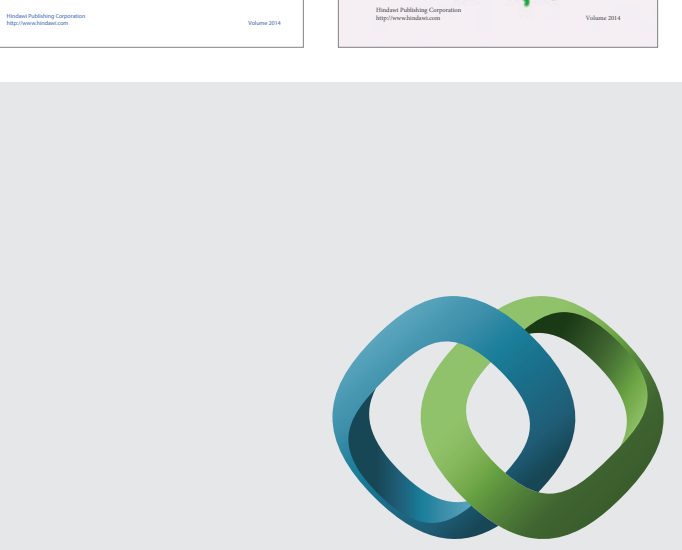

\section{Hindawi}

Submit your manuscripts at

http://www.hindawi.com
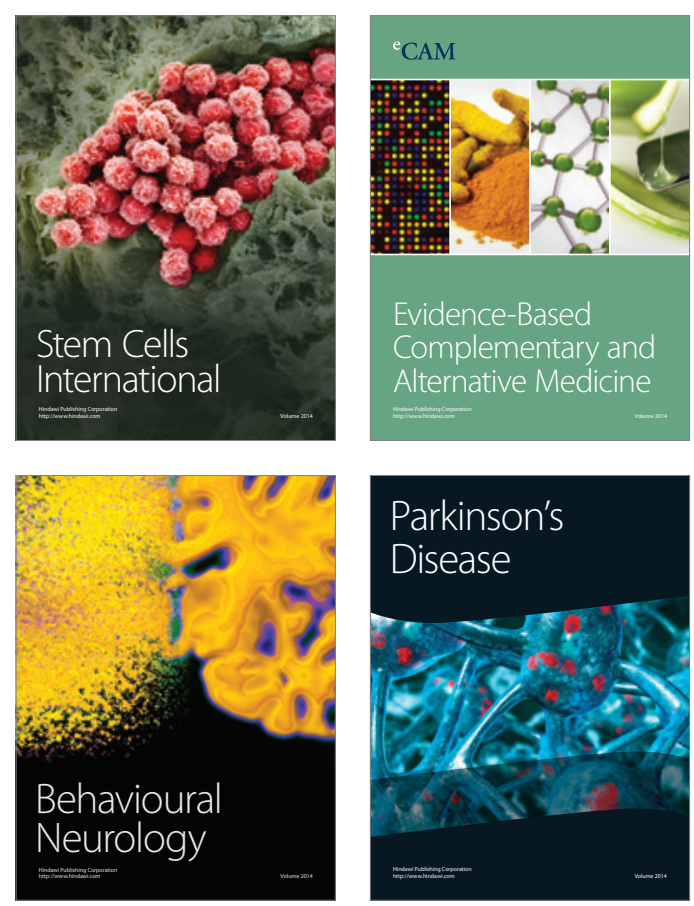

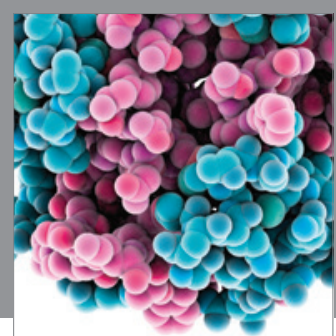

Journal of
Diabetes Research

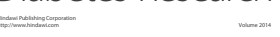

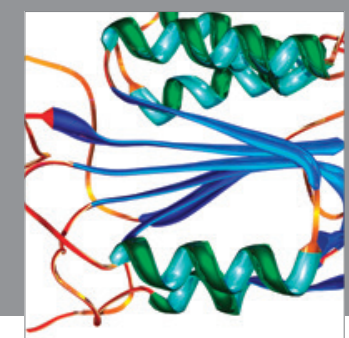

Disease Markers
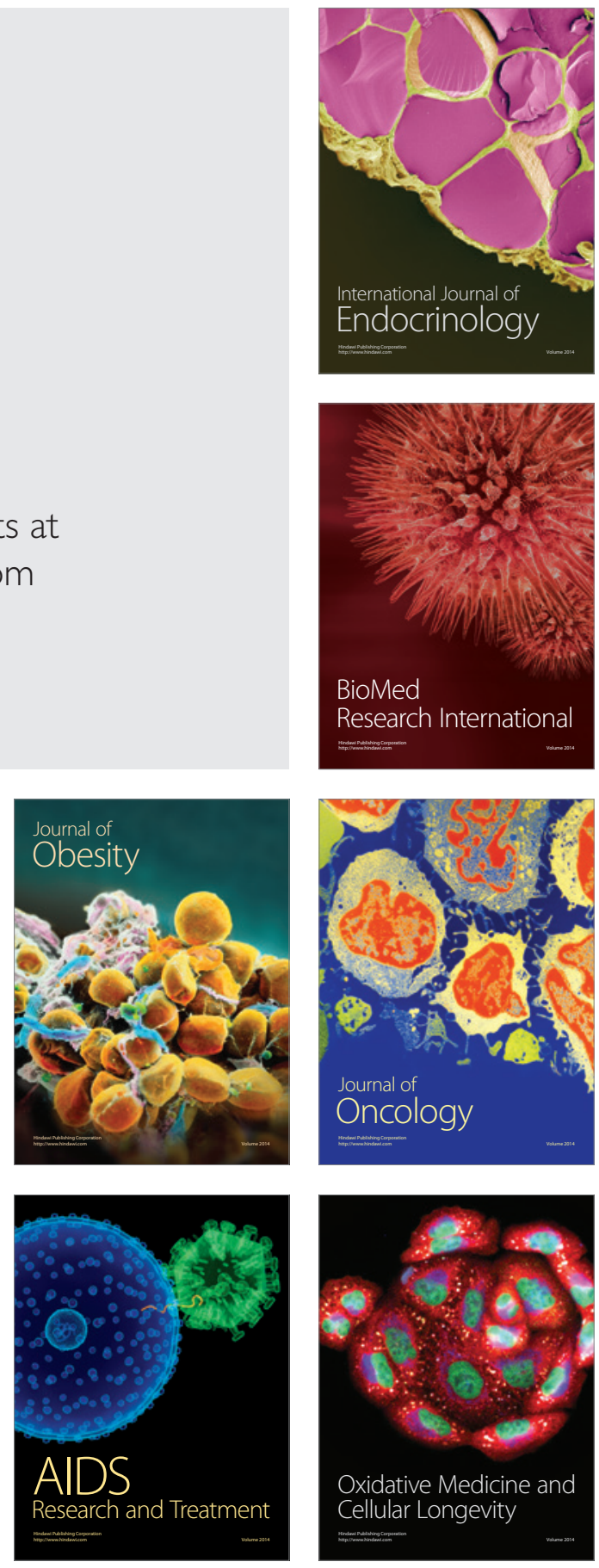